\title{
1 Adaptable Automated Interpretation of Rapid Diagnostic Tests Using Few-Shot Learning
}

3 Siddarth Arumugam ${ }^{1 \dagger}$; Jiawei $\mathrm{Ma}^{2 \dagger}$; Uzay Macar ${ }^{2}$; Guangxing $\mathrm{Han}^{3}$; Kathrine McAulay ${ }^{4}$; Darrell

4 Ingram ${ }^{5}$; Alex Ying ${ }^{1}$; David A. M. Colburn ${ }^{1}$; Robert Stanciu ${ }^{1}$; Thomas Grys ${ }^{4}$; Shih-Fu Chang ${ }^{2,3^{*}}$;

$7 \quad{ }^{1}$ Department of Biomedical Engineering, Columbia University, New York, NY 10027, USA

$8 \quad{ }^{2}$ Department of Computer Science, Columbia University, New York, NY 10027, USA

$9{ }^{3}$ Department of Electrical Engineering, Columbia University, New York, NY 10027, USA

$10{ }^{4}$ Department of Laboratory Medicine and Pathology, Mayo Clinic, Phoenix, AZ 85054, USA

115 Safe Health Systems, Inc., Los Angeles, CA 90036, USA

$13 \dagger$ These authors contributed equally to this article.

$14 *$ Co-corresponding authors.

16 Key words: Few-shot adaptation, rapid diagnostic tests, self-supervision, COVID-19, pandemic

\section{Abstract}

Point-of-care lateral-flow assays (LFAs) are becomingly increasingly prevalent for

21 diagnosing individual patient disease status and surveying population disease prevalence in a

22 timely, scalable, and cost-effective manner, but a central challenge is to assure correct assay

23 operation and results interpretation as the assays are manually performed in decentralized

24 settings. A smartphone-based software can automate interpretation of an LFA kit, but such 
medRxiv preprint doi: https://doi.org/10.1101/2021.06.23.21258927; this version posted June 25, 2021. The copyright holder for this preprint (which was not certified by peer review) is the author/funder, who has granted medRxiv a license to display the preprint in perpetuity.

It is made available under a CC-BY-NC-ND 4.0 International license .

25 algorithms typically require a very large number of images of assays tested with validated

26 specimens, which is challenging to collect for different assay kits, especially for those released

27 during a pandemic. Here, we present an approach - AutoAdapt LFA - that uses few-shot

28 learning, an approach used in other applications such as computer vision and robotics, for

29 accurate and automated interpretation of LFA kits that requires a small number of validated

30 images for training. The approach consists of three components: extraction of membrane and

31 zone areas from an image of the LFA kit, a self-supervised encoder that employs a feature

32 extractor trained with edge-filtered patterns, and few-shot adaptation that enables generalization

33 to new kits using limited validated images. From a base model pre-trained on a commercial LFA

34 kit, we demonstrated the ability of adapted models to interpret results from five new COVID-19

35 LFA kits (three detecting antigens for diagnosing active infection, and two detecting antibodies

36 for diagnosing past infection). Specifically, using just 10 to 20 images of each new kit, we

37 achieved accuracies of $99 \%$ to $100 \%$ for each kit. The server-hosted algorithm has an execution

38 time of approximately 4 seconds, which can potentially enable quality assurance and linkage to

39 care for users operating new LFAs in decentralized settings.

40 
medRxiv preprint doi: https://doi.org/10.1101/2021.06.23.21258927; this version posted June 25, 2021. The copyright holder for this preprint (which was not certified by peer review) is the author/funder, who has granted medRxiv a license to display the preprint in perpetuity.

It is made available under a CC-BY-NC-ND 4.0 International license .

\section{$41 \quad$ Main text}

\section{Introduction}

47 deployment in decentralized settings, such as primary care clinics and homes ${ }^{1-5}$. For example,

48 improper assay operation could produce absent control bands; alternatively, failure to identify

49 the presence of faint bands or confusing the zone type (e.g., control vs. test bands) could lead to

50 an incorrect interpretation of overall assay result ${ }^{6}$. For example, in the COVID-19 pandemic, a

51 number of SARS-CoV-2 antigen tests are now approved for home use ${ }^{7}$ to support decentralized

52 testing; consequently, user errors from incorrect operation and results interpretation are also

53 likely to become more prominent in the coming months to years.

Image-processing algorithms to automate the interpretation of LFAs and rapid diagnostic

56 tests can potentially provide quality assurance to users in decentralized settings and reduce

57 incidence of these errors, but existing algorithms have shortcomings such as the need to use

58 images collected by smartphones with physical attachments ${ }^{5,8-14}$, are designed to work

59 retrospectively with a library of pre-collected images ${ }^{15,16}$, or require a large number of labelled

60 training images ranging in the hundreds ${ }^{17,18}$ for each assay kit. By comparison, an ideal

61 algorithm would be scalable in deployment (for example, working in real time with images

62 collected by a smartphone camera without an extra adapter) and would not require experimental

63 collection of a large number of expert-labelled images with validated clinical specimens across a 
medRxiv preprint doi: https://doi.org/10.1101/2021.06.23.21258927; this version posted June 25, 2021. The copyright holder for this preprint (which was not certified by peer review) is the author/funder, who has granted medRxiv a license to display the preprint in perpetuity.

It is made available under a CC-BY-NC-ND 4.0 International license .

64 large and ever-changing roster of new LFAs, which is especially challenging to achieve during

65 public health emergencies.

66

In this study, we have developed 1) an end-to-end modular workflow to work with assay

68 kit images taken with a smartphone with no external adapters and 2) a trained algorithm that can

69 be adapted to a new assay kit with just 10 to 20 images of the new kit in order to accurately

70 interpret the result (Fig. 1a). The ideal algorithm should generalize to different LFA kits with

71 variations in color and size of bands ${ }^{1,19-22}$ : the color and intensity of bands depend on sizes and

72 shapes of gold nanoparticles ${ }^{20,23}$, material properties of the membrane, and membrane

73 pretreatment steps ${ }^{20,21}$; the sizes of bands depend on liquid-dispensing conditions and capillary

74 flow time ${ }^{20,21}$. Here, we propose a few-shot adaptation strategy - which has been employed in

75 applications ranging from computer vision to robotics ${ }^{24-26}$ to learn a strong classifier for new

76 domains ${ }^{27-31}$ - to mitigate the performance drop caused by domain shift stemming from image-

77 pattern variance, using only a few labeled images. In our few-shot model adaptation strategy,

78 zone areas from many images of a "base" kit are cropped and used to pre-train a feature-

79 extraction network that employs self-supervised learning with edge-filtered images. To adapt to

80 a new assay kit, zone areas from 10 to 20 images are cropped, and the pre-trained model from the

81 base model (shown as "B" in Fig. 1a) adjusts its weights to a model adapted to a new assay

82 (shown as "N" in Fig. 1a) using supervised contrastive learning. Thus, for the end user

83 operating a new assay kit, zone areas from an image of the kit are cropped, and the adapted

84 network automatically and accurately interprets the bands at each zone and overall assay result. 
medRxiv preprint doi: https://doi.org/10.1101/2021.06.23.21258927; this version posted June 25, 2021. The copyright holder for this preprint (which was not certified by peer review) is the author/funder, who has granted medRxiv a license to display the preprint in perpetuity.

It is made available under a CC-BY-NC-ND 4.0 International license .

In this study, we pre-trained a base model using expert-labelled images from the

87 AssureTech EcoTest COVID-19 IgG/IgM Antibody Test, an assay authorized by FDA, and

88 adapted the model to interpret LFAs from five other commercial COVID-19 LFAs (Fig. 1b).

89 The five LFAs include three antigen tests (ACON Flowflex SARS-CoV-2 Antigen Rapid Test,

90 Anhui DeepBlue SARS-CoV-2 Antigen Test, and Jinwofu SARS-CoV-2 Antigen Rapid Test),

91 one antibody test (ACON SARS-CoV-2 IgG/IgM Antibody Test), and an AssureTech EcoTest

92 COVID-19 IgG/IgM Antibody Test kit that uses a different housing (denoted in the paper as

93 'EcoTest (housing 2)') but retains use of the same LFA membrane (Fig. 1b). Like almost all

94 commercial LFAs, these kits share rectangular control and test bands, but differ in kit housing

95 dimensions and membrane dimensions, as well as number, spacing and color of bands (kit-

96 specific dimensions shown in Supplementary Table 1). To illustrate the challenge for

97 interpreting new assay kits, without few-shot adaptation, this pre-trained algorithm produced

98 incorrect predictions (both false positives and false negatives) due to variations in color and

99 intensities of bands and membranes across new LFA kits (Fig. 1c).

100

101 Overview of pipeline

102

103

In the AutoAdapt LFA algorithm (Fig. 1d), a user takes an image of an LFA kit, which

104 enters a cloud-hosted pipeline with an instance-segmentation model that corrects the orientation

105 and perspective of the raw image, segments the assay kit from background and the membrane

106 from assay kit, and crops individual zones (i.e., regions in the membrane corresponding to bands

107 and a portion of surrounding area) from the membrane. Next, images of zones enter a feature-

108 extraction network, which is learned in order to generate robust feature representation as unique 
medRxiv preprint doi: https://doi.org/10.1101/2021.06.23.21258927; this version posted June 25, 2021. The copyright holder for this preprint (which was not certified by peer review) is the author/funder, who has granted medRxiv a license to display the preprint in perpetuity.

It is made available under a CC-BY-NC-ND 4.0 International license .

109 signatures to discriminate positive cases from negative cases under diverse conditions (e.g.,

110 color, intensity, and width of bands); the feature-extraction network also adapts to new LFA kits

111 with a small number of images. From latent feature vectors for each zone, a binary classifier

112 recognizes colored rectangular bands, the form factor seen in the vast majority of $\operatorname{LFAs}^{32,33}$, and

113 determines whether a band is present or absent in each zone. Finally, an assessment of the LFA

114 kit result is obtained by comparing the output of the binary classifier with a lookup table

115 containing all combinations of possible zone-level classification results; this kit-level

116 classification is sent to the user's smartphone as an interpreted LFA result. The server- hosted

117 algorithm has a mean execution time of $3.55 \pm 2.28$ seconds. Overall, this rapid automated

118 interpretation pipeline could fit within a larger digital platform ${ }^{34-37}$ that collects demographic

119 data for epidemiology and provides instructions to carry out the test as well as follow-up linkage

120 to care; Supplementary Fig. 1.

121

122 To develop this pipeline, we framed the objective as learning the optimal parameters of

123 the feature-extraction network and the classifier module by minimizing the loss functions given a

124 set of training images for an assay kit. Unlike methods that require de novo training on a new

125 LFA kit, we developed two novel methods to achieve adaptation requiring only a small number

126 of images of new kits. First, to ensure the underlying feature representation is robust against

127 variations in the LFA images, we developed a feature extractor that learns to extract robust latent

128 representation of zone images for classification; these latent representations are also used to

129 reconstruct (decode) the edges associated with the images. This auxiliary edge reconstruction

130 task is in addition to the standard fully-supervised classification task and helps learn feature

131 representation for effective adaptation, which is based on the observation that edges in an image

132 tend to remain invariant in diverse LFA images. As shown in Fig. 2a, edge-preservation can be 
medRxiv preprint doi: https://doi.org/10.1101/2021.06.23.21258927; this version posted June 25, 2021. The copyright holder for this preprint (which was not certified by peer review) is the author/funder, who has granted medRxiv a license to display the preprint in perpetuity.

It is made available under a CC-BY-NC-ND 4.0 International license .

133 learned in a self-supervised manner (not requiring manually-assigned labels), by using the output

134 of an automatic edge detection algorithm (Sobel filter ${ }^{38}$ ) as the ground truth for decoding.

135 Second, as shown in Fig. 2b, our system performs supervised contrastive learning using a dataset

136 combining images from the new LFA kit and the base LFA kit and learns a new classifier for the

137 new kit. Here, the neural network model pre-trained on a set of labeled LFA images from the

138 base kit is adapted to a new target LFA, using 10 to 20 labelled training images of a new kit.

140 Image pre-processing

For model training as well as during inference, the first module corrected for skew and

143 extracted the zones from the images of LFA kit. This module first detected the orientation of the

144 kit and carried out perspective correction using the predicted segmentation mask of the LFA kit

145 (Supplementary Fig. 2). This mask was generated by using Mask R-CNN ${ }^{39}$, an instance

146 segmentation model (more details in Methods). The kit membrane from the perspective corrected

147 image was then localized and individual test zones were cropped out using the kit-specific

148 dimensions listed in a JSON file. For this study, the test-specific dimensions, such as kit height,

149 kit width, membrane width, membrane height, and zone dimensions, were measured from images

150 of LFA kits using Adobe Photoshop v21.0.2 and saved as a JSON file. These dimensions could

151 be directly provided by the kit manufacturers in the future. To measure the accuracy of the

152 automatic membrane segmentation step, we measure the intersection over union (IoU) scores

153 between the segmented membrane and the manually annotated ground-truth membrane region.

154 IoU scores greater than $90 \%$ for all the assay kits (Table 1) confirm the robustness of this first

155 step. 
medRxiv preprint doi: https://doi.org/10.1101/2021.06.23.21258927; this version posted June 25, 2021. The copyright holder for this preprint (which was not certified by peer review) is the author/funder, who has granted medRxiv a license to display the preprint in perpetuity.

It is made available under a CC-BY-NC-ND 4.0 International license .

Pre-training of feature extractor with edge detection and self-supervised learning

The cropped test zones were fed into a feature extractor and the extracted features were passed into a binary classifier and a decoder (Fig. 2a). The binary classifier (a fully connected

161 layer) outputs ' 0 ' or ' 1 ' to denote the absence or presence of the band in the cropped zone,

162 respectively. The images from the base LFA kit were manually annotated with the binary labels,

163 and the classifier was trained to learn specific prototypes associated with the positive and

164 negative classes using cross-entropy (CE) loss.

Images of kits with faint bands can lead to false negatives while stained membranes and

167 lighting artifacts can lead to false positives (Fig. 1c). Even though such failure cases can be

168 reduced by training on a large number of relevant examples, acquiring sufficient images on a

169 new LFA kit present a logistical challenge. Directly applying the model conventionally trained

170 on the base LFA kit (i.e., by minimizing only the CE loss) to new LFA kits, resulted in low

171 classification accuracy on the new kits. Hence, we designed a self-supervised, edge-enhanced

172 image reconstruction task to improve the generalizability of the feature extractor (Fig. 2a). The

173 network was trained to detect the edges of the image pattern (pixels at the junction between the

174 membrane background and the band in the zone) and reconstruct the corresponding edge-

175 enhanced image. This task is self-supervised: starting with RGB images of zones from a base

176 LFA kit, the model converted the image into grayscale and applied a Sobel filter ${ }^{38}$ to generate the

177 ground truth image set (Sobel filter is a basic image processing algorithm that generates an

178 image emphasizing edges). In parallel, the model fed the extracted features into the decoder to 
medRxiv preprint doi: https://doi.org/10.1101/2021.06.23.21258927; this version posted June 25, 2021. The copyright holder for this preprint (which was not certified by peer review) is the author/funder, who has granted medRxiv a license to display the preprint in perpetuity.

It is made available under a CC-BY-NC-ND 4.0 International license .

179 reconstruct the edge-enhanced image. This model was then trained to minimize the mean

180 squared error (MSE) between the reconstructed edge image from the decoder and the ground

181 truth edge image. By combining the fully-supervised image classification with the self-

182 supervised edge-enhanced image reconstruction, the feature extractor, classifier, and decoder

183 were trained jointly to optimize the zone classification accuracy as well as to learn a good feature

184 representation that is sensitive to edge information.

185

186 Learning a new classifier for a new LFA using few-shot adaptation

The pre-trained model from a base LFA kit was adapted to a new LFA kit with minimal retraining via few-shot adaptation (Fig. 2b). We mixed the labeled data of the base LFA kit and

190 the new LFA kit and used this as the training set. We specifically used this mixture of data from

191 new kit and base kit to avoid overfitting to the small number of images of the new kit. In

192 addition to the CE loss used to train the binary classifier for the new LFA kit, we also used

193 supervised contrastive learning, between the cropped zone images of both the new kit and the

194 base kit, to refine the feature extractor.

We gathered the cropped zone images of both the base kit and the new kit, resampled the

197 data, and calculated the supervised contrastive (SupCT) $\operatorname{loss}{ }^{40}$. First, we extracted features of the

198 base kit cropped zone images for both positive and negative classes and considered them as

199 anchors. Next, we extracted features from the cropped zone images of the new kit and compared

200 them with all of the anchors using cosine similarity. The feature extractor was then trained to

201 maximize the cosine similarity between features of the same class. For the implementation, we 
medRxiv preprint doi: https://doi.org/10.1101/2021.06.23.21258927; this version posted June 25, 2021. The copyright holder for this preprint (which was not certified by peer review) is the author/funder, who has granted medRxiv a license to display the preprint in perpetuity.

It is made available under a CC-BY-NC-ND 4.0 International license .

resampled the cropped zone images from the mixed dataset to build episodes and then computed

203 SupCT loss within each episode (more details in Methods). As a comparison to the adaptation

204 strategy, we also performed fine-tuning which only calculated the CE loss among samples within

205 the episodes for network updating.

206

207 Results

208

209 Description of datasets

210

While gathering the image dataset, we varied imaging conditions by using different

212 phones and imaging the assay kits under varied lighting conditions (more details in Methods).

213 For pre-training of the model, the training dataset from the base kit (AssureTech EcoTest

214 COVID-19 IgG/IgM Antibody Test) consisted of 383 membrane images (674 positive zones and 215475 negative zones). An additional 254 membrane images (441 positive zones and 254 negative

216 zones) were used as the validation set for model selection under the fully-supervised

217 classification task.

In addition, we used a variational autoencoder ${ }^{41}$ to generate a synthetic dataset composed

220 of 600 zones each of faint positive and negative zones ${ }^{42}$. The synthetic data was mixed with the

221 training dataset for the self-supervised edge-reconstruction task.

224 membrane images (168 positive zones and 138 negative zones) of the base kit. The results

225 (Table 2) demonstrate that our model works well for both zone-level classification and overall 
medRxiv preprint doi: https://doi.org/10.1101/2021.06.23.21258927; this version posted June 25, 2021. The copyright holder for this preprint (which was not certified by peer review) is the author/funder, who has granted medRxiv a license to display the preprint in perpetuity.

It is made available under a CC-BY-NC-ND 4.0 International license .

226 kit-level classification on the base kit. A "zone-level” classification accuracy is the model's

227 performance on all the zones for the entire evaluation data set, and "kit-level" classification

228 accuracy is the model's performance in classifying all constituent zones of a single kit (e.g., a

229 kit-level result would be incorrect if any zone in that kit was classified incorrectly). Details

230 regarding the dataset for the five new kits are provided in Supplementary Table 2.

Performance on 5 new COVID-19 tests

We employed the pre-trained feature extractor using the few-shot adaptation strategy on

five COVID-19 LFA kits, and assessed the effects of our adaptation strategy and self-supervised edge-detection task separately. The performance of the base model on the new kits are shown when applied directly and with the proposed adaptation method using 10-shots (20 zone images) highlighting the significant performance improvement seen using our few-shot adaptation strategy (Table 2). On top of the pretrained base model, adaptation can consistently improve the performance by including only a few training images of the new LFA kits. The EcoTest housing 2 kit was identical in all aspects to the base kit expect for the housing, so the direct application of

242 the base model without any adaptation was able to achieve 100\% zone-level and kit-level 243 accuracies.

In Fig. 3, we plot the classification accuracy, at zone level and kit level, against the

246 number of zone images used during the adaptation process, ranging from 0 (direct testing) to

247 using the entire training dataset. These figures also serve as the ablation study evaluating the

248 separate contributions made by self-supervision in pretraining the feature extractor as well as the 249 supervised contrastive learning during adaptation. We compare our adaptation approach with 
medRxiv preprint doi: https://doi.org/10.1101/2021.06.23.21258927; this version posted June 25, 2021. The copyright holder for this preprint (which was not certified by peer review) is the author/funder, who has granted medRxiv a license to display the preprint in perpetuity.

It is made available under a CC-BY-NC-ND 4.0 International license .

250 three alternative approaches: 1) the proposed approach without the self-supervision component

251 in the pre-training stage, 2) the proposed approach without supervised contrastive loss during

252 adaptation, and 3) training the network for a new kit from scratch without the two components.

253 The second approach can be considered as a finetuning process that uses the pre-trained base

254 model and finetunes it with the standard CE loss. For all approaches, the base kit and new kit

255 images were mixed for network training, and the same data sampling strategy was used to ensure

256 a fair comparison.

For each kit, a random set of images of each class were selected from the training dataset

259 for model adaptation and performance of the trained model was validated against a separate

260 evaluation dataset. The plots for the different approaches are compared against the performance

261 upper bound achieved when using all the new images available for training mixed with the base

262 training images for the classification and edge reconstruction tasks. We showed that for each of

263 the kits, Flowflex, DeepBlue, Jinwofu, and ACON IgG/IgM we achieved maximum

264 classification accuracy using just 16, 14, 10, and 18 zone images respectively for the adaptation.

265 For example, we were able to adapt the base model to the Flowflex kit (Fig. 3a) using only eight

266 zone images per class (16 zone images) and reach the same performance $(99.8 \%$ and $99.6 \%$ for

267 the zone and kit levels respectively) as a model trained from scratch using all available training

268 data (200 zone images). The results confirm that both self-supervised pretraining and supervised

269 contrastive loss help, and the combination of these two key ideas helps reach the highest

270 attainable performance. Between these two novel ideas, supervised contrastive learning is more

271 effective: it requires fewer training images during adaptation in order to reach the performance

272 upper bound that is achieved by using the entire training dataset.

273 
medRxiv preprint doi: https://doi.org/10.1101/2021.06.23.21258927; this version posted June 25, 2021. The copyright holder for this preprint (which was not certified by peer review) is the author/funder, who has granted medRxiv a license to display the preprint in perpetuity.

It is made available under a CC-BY-NC-ND 4.0 International license .

In addition, as the feature extractor is pretrained under self-supervision, the extracted

275 features are sensitive to the edges and can work well even when zones with faint bands are

276 encountered. Even though the ACON IgG/IgM kit had the highest frequency of faint bands in

277 our dataset, our approach was able to reach the same performance as using entire training dataset

278 (Fig. 3d) using only nine images of each class (18 zone images). Adaptation without supervised

279 contrastive learning can also reach the same performance using 40-shot adaptation. For the

280 model trained without self-supervised pretraining 70 images (with SupCT loss) and 100 images

281 (without SupCT loss) of each class were required to reach the best performance. In addition,

282 direct testing performance (0-shot adaptation) of the model pretrained on the base kit was higher

283 when trained using self-supervision than when trained using only the CE loss.

Table 3 shows the confusion matrices of the performance of the optimum shot adaptation

when evaluated on the evaluation dataset. By starting with a base model pretrained on an

287 existing LFA kit (AssureTech EcoTest COVID-19 IgG/IgM antibody assay kit), we have shown

288 that it is possible to adapt the existing model to different assay kits, which have different

289 numbers of test lines and form factors, using a small fraction of the images needed to train the

290 base model with no loss in accuracy. In addition to evaluating the confusion matrix among on

291 samples in the evaluation set, we devised an ambiguity region to evaluate the distribution of

292 detection scores (probability of positive class). The ambiguity region is bounded by the detection

293 score thresholds such that an image will be correctly classified only if the probability of the

294 ground truth class is high. The thresholds can be either manually set or statistically estimated

295 with $95 \%$ area under the curve (more details in Methods). We checked the detection scores of all

296 the images in the evaluation dataset against the ambiguity regions and those images with scores

297 falling in ambiguity region were not classified. We computed the percentage of images that were 
medRxiv preprint doi: https://doi.org/10.1101/2021.06.23.21258927; this version posted June 25, 2021. The copyright holder for this preprint (which was not certified by peer review) is the author/funder, who has granted medRxiv a license to display the preprint in perpetuity.

It is made available under a CC-BY-NC-ND 4.0 International license .

categorized as ambiguous as well as the accuracy over the images that were classified. Since the detection score for the false predictions were close to 0.5 , they fell into the ambiguity region.

Therefore, by using this concept of the ambiguity region we were able to treat most of the failure cases as ambiguous while keeping the number of true predictions that fell into the ambiguity region to a minimum. This further increased the classification accuracy among the classified samples consistently over four new target kits (Table 3).

\section{Conclusions and future work} than what was used for training the base model. Compared to de novo training on every new assay kit, this reduction in the number of images was achieved by adopting a modular approach

312 to the machine-learning pipeline: starting from an image of the kit, the perspective-corrected

313 membrane and individual zones were extracted followed by the extraction of the features

314 preserving edge information, and finally a binary output which indicated whether a band was

315 present in the cropped zone. A robust feature extractor is important for handling challenging 316 images in LFA kits like those with faint or partially formed lines. Our approach of using self-

317 supervision to extract features preserving edge information addressed this issue, and it is

318 believed that this use of self-supervised learning to reconstruct edge-enhanced images has not

319 been previously demonstrated. To our knowledge, the application few-shot learning, including

320 this adaptation framework, has not been demonstrated for interpretation of LFA kit images. 
medRxiv preprint doi: https://doi.org/10.1101/2021.06.23.21258927; this version posted June 25, 2021. The copyright holder for this preprint (which was not certified by peer review) is the author/funder, who has granted medRxiv a license to display the preprint in perpetuity.

It is made available under a CC-BY-NC-ND 4.0 International license .

321 Thus, we have shown that using this novel approach, we can train accurate classification models

322 using a fraction of kit images that would be required in de novo training.

In terms of impact for medicine, this reduction in new training images to achieve assured user interpretation of rapid test images is significant with the rise of use of rapid diagnostic tests.

326 Most immediately, the COVID-19 pandemic has thrusted front and forward the need for rapid

327 testing and population surveillance to track and control the spread of the disease in a scalable and

328 timely manner. If effectively implemented, point-of-care testing can contribute significantly to a

329 rapid and effective public health response - as well as patients' individual safety, privacy,

330 physical health and mental well-being - by enabling widespread timely testing in a manner that

331 does not overwhelm the limited capacity of testing facilities or provoke social crowding at

332 selected testing sites. By expediting the process of training a model to newly available rapid

333 diagnostic tests, the AutoAdapt LFA approach could facilitate reliable decentralized testing and

334 real-time monitoring of disease prevalence. In the longer term, the need to achieve assured user

335 interpretation will rise as patients and consumers will more frequently monitor their health via

336 self-testing for both infectious diseases and chronic conditions, in an age of precision health.

337 Future work includes validation on a wider variety of rapid tests, and generalization to LFA kits

338 beyond rectangular bands (for example, as in some vertical flow assays) and bands of single

339 colors (for example, some urinalysis kits with color-based readouts). 
medRxiv preprint doi: https://doi.org/10.1101/2021.06.23.21258927; this version posted June 25, 2021. The copyright holder for this preprint (which was not certified by peer review) is the author/funder, who has granted medRxiv a license to display the preprint in perpetuity.

It is made available under a CC-BY-NC-ND 4.0 International license .

Methods

\section{Dataset Collection}

Base kit (AssureTech EcoTest COVID-19 IgG/IgM Antibody Test): train and validation

344 datasets were gathered using iPhone $\mathrm{X}$ at the Mayo Clinic Hospital, Phoenix, AZ. The evaluation

345 dataset images were gathered using three phones by two users: iPhone X, iPhone 7, Samsung

346 Galaxy J3 (SM-J337V). Care was taken to ensure that the kits were imaged under three different

347 ambient lighting conditions (warm white, cool white, and daylight).

Novel kits (ACON Flowflex SARS-CoV-2 Antigen Rapid Test, Anhui DeepBlue SARS-CoV-2

350 Antigen Test, Jinwofu SARS-CoV-2 Antigen Rapid Test, and ACON SARS-CoV-2 IgG/IgM

351 Antibody Test ): training and evaluation sets were gathered using iPhone $\mathrm{X}$ at the Mayo Clinic

352 Hospital, Phoenix, AZ. Serum samples for the antibody tests were collected under Mayo Clinic

353 IRB 20-004544 or shared by the Department of Laboratory Medicine at the University of

354 Washington School of Medicine (Seattle, WA) ${ }^{43}$. The use of excess clinical specimens was

355 reviewed by the Mayo Clinic Biospecimens Committee and an appropriate Material Transfer

356 Agreement was drawn up to allow access to de-identified specimens from the University of

357 Washington School of Medicine. The University of Washington IRB approved this work with a

358 consent waiver. Nasopharyngeal swabs from Mayo Clinic Hospital patients were heat fixed and

359 run for the antigen tests under Mayo Clinic IRB 20-010688. All necessary patient/participant

360 consent has been obtained and the appropriate institutional forms have been archived.

361 All assay kits were imaged within 10 minutes of running the test. 
medRxiv preprint doi: https://doi.org/10.1101/2021.06.23.21258927; this version posted June 25, 2021. The copyright holder for this preprint (which was not certified by peer review) is the author/funder, who has granted medRxiv a license to display the preprint in perpetuity.

It is made available under a CC-BY-NC-ND 4.0 International license .

\section{Image acquisition and pre-processing based on Mask R-CNN}

The image processing workflow starts with an image of the assay kit being taken by the user through the SMARTtest application ${ }^{18}$ in a fixed portrait orientation. This image is saved in an AWS S3 bucket as an JPEG image from the frontend, and the corresponding URL is sent to the AWS Lambda Function. The function reads the image data, stores the original resolution image in a copy, and resizes the image while preserving the aspect ratio by capping the height of the image to a maximum of 800 pixels. The membrane is localized in the resized image using the instance segmentation model Mask RCNN (Supplementary Fig. 2), and the predicted bounding box coordinates in the resized image are then transformed to the corresponding coordinates in the

372 image of the original resolution to get the highest possible resolution of the membrane which is 373 then sent to the classifier. and combines them with a fully-convolutional network (FCN) and introduces object mask

377 prediction (i.e., segmentation ${ }^{46}$ ) in parallel to bounding box regression. Given an input image, the 378 model extracts feature maps via a pretrained deep neural network (e.g., VGG16), and

379 subsequently passes these in parallel through a ROI-specialized pooling layer followed by

380 several fully-connected layers and an FCN. The instance segmentation model has been trained

381 for two object classes: the kit and the membrane. The model outputs i) detection scores, ii)

382 bounding boxes, and iii) segmentation masks of a maximum of 100 objects. The bounding box

383 defines a rectangular area that contains the assay kit or the membrane. The segmentation mask

384 includes all the pixels that correspond to the actual area of the assay kit or the membrane and do

385 not necessarily have to be rectangular in shape. From all the detected objects we retain 
medRxiv preprint doi: https://doi.org/10.1101/2021.06.23.21258927; this version posted June 25, 2021. The copyright holder for this preprint (which was not certified by peer review) is the author/funder, who has granted medRxiv a license to display the preprint in perpetuity.

It is made available under a CC-BY-NC-ND 4.0 International license .

386 information for a kit and membrane object with the highest detection score greater than 0.9.

387 Supplementary Fig. 3 illustrates different IoU scores and the corresponding membrane

388 segmentation masks for the EcoTest (base kit).

389

The bounding boxes and segmentation masks of the kit and membrane with the highest

391 detection score are retrieved and a binary segmentation mask is generated for both kit and

392 membrane. Next, the rotation angle is estimated by performing contour detection on the

393 segmentation mask of the kit and membrane, and approximating a minimum-area quadrilateral

394 mask whose corner coordinates can be used to construct a right-angle triangle. The membrane is

395 cropped from the input image with the binary segmentation mask, and is subsequently rotated by

396 the estimated angle. The rotated membrane will have black regions if the estimated angle is

397 greater than zero, and the largest rectangle that doesn't include any black pixels is estimated and

398 extracted as the final membrane to be sent to the classifier. Additionally, we have the capability

399 to compute the homography matrix ${ }^{47}$ between the predicted segmentation mask and bounding

400 box of the kit, and use it to transform the kit of the image to correct for distortion along the pitch

401 axis.

402

403 Pre-training with self-supervised learning

404

405

The model uses the Mean Squared Error (MSE) between the decoder output (the

406 reconstructed image) and the ground truth edge-enhanced image as the loss. For the base kit, the

407 number of labeled images were sufficient so that both the classification and the edge-enhanced

408 image reconstruction tasks were carried out to learn a good feature extractor. Thus, as shown in 
medRxiv preprint doi: https://doi.org/10.1101/2021.06.23.21258927; this version posted June 25, 2021. The copyright holder for this preprint (which was not certified by peer review) is the author/funder, who has granted medRxiv a license to display the preprint in perpetuity.

It is made available under a CC-BY-NC-ND 4.0 International license .

409 Fig. 2a output features of each cropped zone are sent to both the classifier and the decoder. The

410 model uses the cross-entropy (CE) loss for the classification task and uses the MSE between the

411 reconstruction and the automatically reconstructed edge filtered image to learn the optimal

412 convolution kernel in the decoder for the self-supervised edge reconstruction task. By using the

413 edge-enhanced features, the feature extractor was able to generalize well on new assay kit

414 images even if the zones were faint.

415

To generate the ground-truth of the self-supervision task, the model first converted the

417 RGB image into a grayscale image, and then performed edge filtering using Sobel filtering to

418 highlight the pixels in the edge region (if an edge exists). The edge filtered images are then

419 normalized between 0 and 1 and set as labels for the self-supervision task.

420

With the annotated classification label and the self-generated edge detection label, the equally weighted CE loss and MSE were summed up and used as the objective. In this manner,

423 the extracted features were made sensitive to the edge region and the encoded edge information 424 was used for the classification of cropped zone images including those with faint bands.

426 Hyperparameter Selection

Instance segmentation model structure:

We used the ResNet50 CNN as the backbone of the Mask R-CNN and pretrained it on

430 the ImageNet1K dataset for model initialization. The backbone has been trained on ImageNet1K 
medRxiv preprint doi: https://doi.org/10.1101/2021.06.23.21258927; this version posted June 25, 2021. The copyright holder for this preprint (which was not certified by peer review) is the author/funder, who has granted medRxiv a license to display the preprint in perpetuity.

It is made available under a CC-BY-NC-ND 4.0 International license .

431 as a fully-supervised image classification task among 1,000 classes. We used a hidden layer size

432 of 256 for the mask predictor.

434 Instance segmentation training:

435 We used 50 epochs and Adam optimizer for all of the training processes. We pretrained

436 the model on a training subset of 50 images of the base kit with a learning rate of $5 \mathrm{E}-5$ and

437 achieved an IOU score of 0.93 on an evaluation set of ten images. We then finetuned the model

438 on the new assay kits with a learning rate of 5E-6 using 10 training images and evaluated the

439 performance on 10 evaluation images. We used the following train-time augmentations: (i)

440 horizontal flip, (ii) scaling, (iii) aspect-ratio modification, (iv) brightness adjustment, (v) contrast

441 adjustment, (vi) hue adjustment, (vii) saturation adjustment, (viii) color distortion, (ix) jitter

442 addition, (x) cropping, (xi) padding, and (xii) Gaussian noise addition. Supplementary Table 3

443 shows the results from the test of robustness of the instance segmentation model using

444 bootstrapping.

446 Classification model structure:

447 We used the ResNet18 CNN as the feature extractor and pretrained the model on the

448 ImageNet1K dataset for model initialization ${ }^{48}$. The feature extractor has been trained on

449 ImageNet1 $\mathrm{K}$ as a fully-supervised image classification task among 1,000 classes. As shown in

450 Fig. 2a, during the pretraining on base kit images, classifier is configured as a fully connected

451 layer (top output) and the decoder is configured as a stack of three deconvolution layers (bottom

452 output). 
medRxiv preprint doi: https://doi.org/10.1101/2021.06.23.21258927; this version posted June 25, 2021. The copyright holder for this preprint (which was not certified by peer review) is the author/funder, who has granted medRxiv a license to display the preprint in perpetuity.

It is made available under a CC-BY-NC-ND 4.0 International license .

\section{Classification model pre-training:}

Given a training set, all the images were fed into the model in sequence and the loss was calculated for both gradient backpropagation and for updating the model. A single epoch is completed when the model has seen all the images once. 90 epochs were run in our training process. The performance of the model on the validation dataset was determined after each epoch and the model achieving the highest accuracy was selected.

\section{Classification model adaptation \& finetuning:}

The network was trained for 100 epochs for each of the new kits with a learning rate of 0.001. Within each epoch, we sample 30 episodes and set Q (number of samples per class) as 32 for each episode. The feature extractor was tuned with a learning rate of 0.0001. Adam optimizer was used for the network parameter update of both the feature extractor and the classifier. The inbuilt PyTorch image transformation functions were used, namely: 1) horizontal flip, 2)

Random Rotation, 3) Color Jitter (including grayscale). Supplementary Table 4 shows the results from the test of robustness of the adapted model on the 4 new test kits using bootstrapping.

\section{Classification model training from scratch:}

Similar to the initialization step before self-supervision, a ResNet $18 \mathrm{CNN}$ is used as the

$$
\text { feature extractor which has been trained with the ImageNet1K dataset as a fully-supervised }
$$

image classification task. The network is then trained on the training images of the new assay kit with Adam optimizer and a learning rate of 0.001 . The same transformation functions used for the adaptation were used here. 
medRxiv preprint doi: https://doi.org/10.1101/2021.06.23.21258927; this version posted June 25, 2021. The copyright holder for this preprint (which was not certified by peer review) is the author/funder, who has granted medRxiv a license to display the preprint in perpetuity.

It is made available under a CC-BY-NC-ND 4.0 International license .

Threshold Determination and Ambiguity Region

In general, the thresholds $\left(\delta_{\text {neg }}, \delta_{\text {pos }}\right)$ for negative class and positive class were determined

481 individually by feeding the detection score (probability of positive, $P_{\text {pos }}$ ) of all images of each

482 class into the statistical model and fitting separately. Using the threshold determination of

483 positive class as an example, the steps are explained below:

484 1) Select the Inverse Gaussian Distribution as the model template to be fitted ${ }^{49,50}$. The reasons why we select this one-side distribution model are,

a. The inverse gaussian distribution is used to model variables of non-negative values.

b. Since the probability output from the model is between 0 and 1 , the inverse gaussian distribution is selected as it is tighter within the range $[0,1]$ (i.e., the area under its probability density function (PDF) curve within $[0,1]$ is closer to one), compared to other distribution models such as Gamma distribution which may have an observable tail in [1, infinity) interval.

2) Feed the $P_{\text {pos }}$ of all labelled positive zone images into the statistical model and use the fitted parameters to draw the PDF curve.

3) We set the area under the probability distribution curve (between the threshold and the extreme value, i.e., 1 for positive and 0 for negative) as $95 \%$ and use Divide and Conquer 
medRxiv preprint doi: https://doi.org/10.1101/2021.06.23.21258927; this version posted June 25, 2021. The copyright holder for this preprint (which was not certified by peer review) is the author/funder, who has granted medRxiv a license to display the preprint in perpetuity.

It is made available under a CC-BY-NC-ND 4.0 International license .

For a negative class, $P_{p o s}$ is still used as input to find the classification score threshold $\delta_{n e g}$.

500 For the convenience of presentation, $\left[\delta_{n e g}, \delta_{\text {pos }}\right]$ is used to denote the ambiguity region where

501 images with $\delta_{\text {neg }} \leq P_{\text {pos }} \leq \delta_{\text {pos }}$ will not be classified since they fall within the region, and the

502 images with $P_{p o s} \leq \delta_{\text {neg }}$ or $P_{\text {pos }} \geq \delta_{\text {pos }}$ are classified as negative or positive respectively. The

503 ratio of the unclassified images with respect to the entire evaluation set is reported as the

504 percentage of ambiguous cases (as shown in Table 3).

505

506

507

5081 Posthuma-Trumpie, G. A., Korf, J., van Amerongen, A. J. A. \& chemistry, b. Lateral

509 flow (immuno) assay: its strengths, weaknesses, opportunities and threats. A literature

$510 \quad$ survey. 393, 569-582 (2009).

5112 Andryukov, B. G. J. A. M. Six decades of lateral flow immunoassay: from determining

512 metabolic markers to diagnosing COVID-19. 6, 280-304 (2020).

5133 Ibitoye, M., Frasca, T., Giguere, R., Carballo-Diéguez, A. J. A. \& Behavior. Home

514 testing past, present and future: lessons learned and implications for HIV home tests. 18,

$515 \quad 933-949(2014)$.

5164 Koczula, K. M. \& Gallotta, A. Lateral flow assays. Essays in biochemistry 60, 111-120

$517 \quad(2016)$

5185 Carrio, A., Sampedro, C., Sanchez-Lopez, J. L., Pimienta, M. \& Campoy, P. Automated 519 low-cost smartphone-based lateral flow saliva test reader for drugs-of-abuse detection.

$520 \quad$ Sensors-Basel 15, 29569-29593 (2015). 
medRxiv preprint doi: https://doi.org/10.1101/2021.06.23.21258927; this version posted June 25, 2021. The copyright holder for this preprint (which was not certified by peer review) is the author/funder, who has granted medRxiv a license to display the preprint in perpetuity.

It is made available under a CC-BY-NC-ND 4.0 International license .

5216 Ghani, A. C., Burgess, D. H., Reynolds, A. \& Rousseau, C. Expanding the role of diagnostic and prognostic tools for infectious diseases in resource-poor settings. Nature 528, S50-52, doi:10.1038/nature16038 (2015).

5247 FDA. In Vitro Diagnostics EUAs - Antigen Diagnostic Tests for SARS-CoV-2, <https://www.fda.gov/medical-devices/coronavirus-disease-2019-covid-19-emergency-

526 use-authorizations-medical-devices/in-vitro-diagnostics-euas-antigen-diagnostic-tests-

$527 \quad$ sars-cov-2> $(2021)$.

5288 Ballard, Z. S. et al. Deep learning-enabled point-of-care sensing using multiplexed paper-

$529 \quad$ based sensors. 3, 1-8 (2020).

5309 Joung, H.-A. et al. Point-of-care serodiagnostic test for early-stage lyme disease using a 531 multiplexed paper-based immunoassay and machine learning. 14, 229-240 (2019).

53210 Contreras-Naranjo, J. C., Wei, Q. \& Ozcan, A. J. I. J. o. S. T. i. Q. E. Mobile phone533 based microscopy, sensing, and diagnostics. 22, 1-14 (2015).

53411 Kong, J. E. et al. Highly Stable and Sensitive Nucleic Acid Amplification and Cell535 Phone-Based Readout. Acs Nano 11, 2934-2943, doi:10.1021/acsnano.6b08274 (2017).

53612 Potluri, V. et al. An inexpensive smartphone-based device for point-of-care ovulation 537 testing. 19, 59-67 (2019).

53813 Shah, K. G., Singh, V., Kauffman, P. C., Abe, K. \& Yager, P. J. A. c. Mobile phone 539 ratiometric imaging enables highly sensitive fluorescence lateral flow immunoassays 540 without external optical filters. 90, 6967-6974 (2018).

54114 Dell, N. \& Borriello, G. in Proceedings of the 3rd ACM Symposium on Computing for $542 \quad$ Development. 1-10. 
medRxiv preprint doi: https://doi.org/10.1101/2021.06.23.21258927; this version posted June 25, 2021. The copyright holder for this preprint (which was not certified by peer review) is the author/funder, who has granted medRxiv a license to display the preprint in perpetuity.

It is made available under a CC-BY-NC-ND 4.0 International license .

54315 Ruppert, C., Phogat, N., Laufer, S., Kohl, M. \& Deigner, H.-P. J. M. A. A smartphone readout system for gold nanoparticle-based lateral flow assays: application to monitoring of digoxigenin. 186, 119 (2019).

54616 Dell, N. L., Venkatachalam, S., Stevens, D., Yager, P. \& Borriello, G. in Proceedings of 547 the 5th ACM workshop on Networked systems for developing regions. 3-8.

54817 Draz, M. S. et al. Virus detection using nanoparticles and deep neural network-enabled smartphone system. Sci Adv 6, doi:10.1126/sciadv.abd5354 (2020).

55018 Balán, I. C. et al. SMARTtest: A Smartphone App to Facilitate HIV and Syphilis Self551 and Partner-Testing, Interpretation of Results, and Linkage to Care. AIDS and Behavior,

55319 Aveyard, J., Mehrabi, M., Cossins, A., Braven, H. \& Wilson, R. J. C. c. One step visual detection of PCR products with gold nanoparticles and a nucleic acid lateral flow (NALF) device. 4251-4253 (2007).

55620 Parolo, C. et al. Tutorial: design and fabrication of nanoparticle-based lateral-flow 557 immunoassays. 15, 3788-3816 (2020).

55821 Millipore, E. J. E. M. C. B., MA, USA. Rapid lateral flow test strips: Considerations for 559 product development. 29, $702-707$ (2013).

56022 Yetisen, A. K., Akram, M. S. \& Lowe, C. R. Paper-based microfluidic point-of-care diagnostic devices. Lab Chip 13, 2210-2251, doi:10.1039/c3lc50169h (2013).

56223 Huang, X. \& El-Sayed, M. A. J. J. o. a. r. Gold nanoparticles: Optical properties and 563 implementations in cancer diagnosis and photothermal therapy. 1, 13-28 (2010).

56424 Lake, B. M., Salakhutdinov, R. \& Tenenbaum, J. B. J. S. Human-level concept learning through probabilistic program induction. 350, 1332-1338 (2015). 
medRxiv preprint doi: https://doi.org/10.1101/2021.06.23.21258927; this version posted June 25, 2021. The copyright holder for this preprint (which was not certified by peer review) is the author/funder, who has granted medRxiv a license to display the preprint in perpetuity.

It is made available under a CC-BY-NC-ND 4.0 International license .

56625 Wang, Y., Yao, Q., Kwok, J. T. \& Ni, L. M. J. A. C. S. Generalizing from a few

567 examples: A survey on few-shot learning. 53, 1-34 (2020).

56826 Wu, Y. \& Demiris, Y. in 2010 IEEE International Conference on Robotics and

$569 \quad$ Automation. 2889-2894 (IEEE).

57027 Snell, J., Swersky, K. \& Zemel, R. in Advances in neural information processing systems.

$571 \quad 4077-4087$.

57228 Kang, B. et al. in Proceedings of the IEEE International Conference on Computer Vision.

$573 \quad 8420-8429$.

57429 Wang, Y.-X., Ramanan, D. \& Hebert, M. in Proceedings of the IEEE International

575 Conference on Computer Vision. 9925-9934.

57630 Sun, Q., Liu, Y., Chua, T.-S. \& Schiele, B. in Proceedings of the IEEE conference on

577 computer vision and pattern recognition. 403-412.

$57831 \quad$ Wang, Y.-X. \& Hebert, M. in European Conference on Computer Vision. 616-634

$579 \quad$ (Springer).

58032 Sajid, M., Kawde, A.-N. \& Daud, M. J. J. o. S. C. S. Designs, formats and applications of

$581 \quad$ lateral flow assay: A literature review. 19, 689-705 (2015).

58233 Bahadır, E. B. \& Sezgintürk, M. K. J. T. T. i. A. C. Lateral flow assays: Principles,

583 designs and labels. 82, 286-306 (2016).

58434 Budd, J. et al. Digital technologies in the public-health response to COVID-19. Nat Med

585 26, 1183-1192, doi:10.1038/s41591-020-1011-4 (2020).

58635 Wood, C. S. et al. Taking connected mobile-health diagnostics of infectious diseases to

587 the field. Nature 566, 467-474, doi:10.1038/s41586-019-0956-2 (2019). 
medRxiv preprint doi: https://doi.org/10.1101/2021.06.23.21258927; this version posted June 25, 2021. The copyright holder for this preprint (which was not certified by peer review) is the author/funder, who has granted medRxiv a license to display the preprint in perpetuity. It is made available under a CC-BY-NC-ND 4.0 International license .

58836 Whitelaw, S., Mamas, M. A., Topol, E. \& Van Spall, H. G. J. T. L. D. H. Applications of digital technology in COVID-19 pandemic planning and response. (2020).

59037 Murray, C. J., Alamro, N. M. S., Hwang, H. \& Lee, U. J. T. L. P. H. Digital public health $591 \quad$ and COVID-19. 5, e469-e470 (2020).

59238 Kittler, J. J. I. \& Computing, V. On the accuracy of the Sobel edge detector. 1, 37-42 $593 \quad$ (1983).

59439 He, K., Gkioxari, G., Dollar, P. \& Girshick, R. Mask R-CNN. IEEE Trans Pattern Anal 595 Mach Intell 42, 386-397, doi:10.1109/TPAMI.2018.2844175 (2020).

$59640 \quad$ Khosla, P. et al. Supervised contrastive learning. (2020).

59741 Kingma, D. P. \& Welling, M. J. a. p. a. Auto-encoding variational bayes. (2013).

59842 Wan, Z., Zhang, Y.\& He, H. in 2017 IEEE symposium series on computational 599 intelligence (SSCI). 1-7 (IEEE).

60043 McAulay, K. et al. Retrospective clinical evaluation of 4 lateral flow assays for the 601 detection of SARS-CoV-2 IgG. 98, 115161 (2020).

60244 Ren, S., He, K., Girshick, R. \& Sun, J. Faster R-CNN: Towards Real-Time Object 603 Detection with Region Proposal Networks. IEEE Trans Pattern Anal Mach Intell 39, 604 1137-1149, doi:10.1109/TPAMI.2016.2577031 (2017).

60545 Girshick, R. in Proceedings of the IEEE international conference on computer vision. $606 \quad 1440-1448$

60746 Minaee, S. et al. Image segmentation using deep learning: A survey. (2021).

60847 Geetha Kiran, A. \& Murali, S. J. J. C. S. A. Automatic rectification of perspective 609 distortion from a single image using plane homography. 3, 47-58 (2013). 
medRxiv preprint doi: https://doi.org/10.1101/2021.06.23.21258927; this version posted June 25, 2021. The copyright holder for this preprint (which was not certified by peer review) is the author/funder, who has granted medRxiv a license to display the preprint in perpetuity.

It is made available under a CC-BY-NC-ND 4.0 International license .

61048 Deng, J. et al. in 2009 IEEE conference on computer vision and pattern recognition.

$611 \quad 248-255$ (Ieee).

61249 Folks, J. L. \& Chhikara, R. S. J. J. o. t. R. S. S. S. B. The inverse Gaussian distribution

613 and its statistical application-a review. 40, 263-275 (1978).

61450 Chhikara, R. The inverse Gaussian distribution: theory: methodology, and applications.

615 Vol. 95 (CRC Press, 1988).

616

617 Acknowledgements

We thank Ken Mayer for his involvement in the coordination of the study. Assay kits were kindly provided to Mayo Clinic for evaluations from Acon, Paramount (DeepBlue and

621 Jinwofu), EcoTest (EcoTest Housing 2), and BTNX (EcoTest Housing 1). The work was

622 supported by Herbert Irving Comprehensive Cancer Center in partnership with the Irving

623 Institute for Clinical and Translational Research via a SARS-CoV-2 Research Pilot Grant,

624 Columbia University School of Engineering and Applied Science via a Technology Innovations

625 for Urban Living in the Face of COVID-19 Pilot Grant, and a gift from Bing Zhao.

\section{Author contributions}

S.A., U.M., and S.K.S., conceptualized the initial project. S.A., J.M, S.C., and S.K.S. supervised the project. U.M. developed the object detection module. J.M., G.H., and S.C. developed the feature extractor and few-shot adaptation modules. D.I. and U.M. worked on cloud architecture and model hosting. A.Y. developed an image-labelling dashboard. D.C. 
medRxiv preprint doi: https://doi.org/10.1101/2021.06.23.21258927; this version posted June 25, 2021. The copyright holder for this preprint (which was not certified by peer review) is the author/funder, who has granted medRxiv a license to display the preprint in perpetuity.

It is made available under a CC-BY-NC-ND 4.0 International license .

636 developed the workflow to record kit parameters. S.A, J.M., U.M., S.C., and S.K.S. analyzed the

637 data. K.M. and T.G. tested the assay kits with clinical samples and acquired smartphone images.

638 R.S. helped label images for object detection. S.A., J.M., U.M., S.C., and S.K.S. wrote the

639 manuscript.

640

641

642 Competing interests

643

644

645 Systems, Inc.

646

647 Author Declarations

648 I confirm all relevant ethical guidelines have been followed, and any necessary IRB and/or ethics

649 committee approvals have been obtained.

650 Yes

651 The details of the IRB/oversight body that provided approval or exemption for the research

652 described are given below:

653 Serum samples for the antibody tests were collected under Mayo Clinic IRB 20-004544 or

654 shared by the Department of Laboratory Medicine at the University of Washington School of

655 Medicine (Seattle, WA). The use of excess clinical specimens was reviewed by the Mayo Clinic

656 Biospecimens Committee and an appropriate Material Transfer Agreement was drawn up to

657 allow access to de-identified specimens from the University of Washington School of Medicine. 
medRxiv preprint doi: https://doi.org/10.1101/2021.06.23.21258927; this version posted June 25, 2021. The copyright holder for this preprint (which was not certified by peer review) is the author/funder, who has granted medRxiv a license to display the preprint in perpetuity.

It is made available under a CC-BY-NC-ND 4.0 International license .

658 The University of Washington IRB approved this work with a consent waiver. Nasopharyngeal

659 swabs from Mayo Clinic Hospital patients were heat fixed and run for the antigen tests under

660 Mayo Clinic IRB 20-010688.

661

662 All necessary patient/participant consent has been obtained and the appropriate institutional

663 forms have been archived.

664 Yes

665 I understand that all clinical trials and any other prospective interventional studies must be

666 registered with an ICMJE-approved registry, such as ClinicalTrials.gov. I confirm that any such

667 study reported in the manuscript has been registered and the trial registration ID is provided

668 (note: if posting a prospective study registered retrospectively, please provide a statement in the

669 trial ID field explaining why the study was not registered in advance).

$670 \mathrm{n} / \mathrm{a}$

671 I have followed all appropriate research reporting guidelines and uploaded the relevant

672 EQUATOR Network research reporting checklist(s) and other pertinent material as

673 supplementary files, if applicable.

674 Yes 
medRxiv preprint doi: https://doi.org/10.1101/2021.06.23.21258927; this version posted June 25, 2021. The copyright holder for this preprint (which was not certified by peer review) is the author/funder, who has granted medRxiv a license to display the preprint in perpetuity.

It is made available under a CC-BY-NC-ND 4.0 International license .

\section{Tables}

676

\begin{tabular}{|c|c|}
\hline Kit name & IOU score \\
\hline Flowflex & 0.92 \\
\hline DeepBlue & 0.89 \\
\hline Jinwofu & 0.90 \\
\hline ACON IgG/IgM & 0.93 \\
\hline EcoTest housing 2 & 0.93 \\
\hline
\end{tabular}

678 Table 1. Intersection over Union scores for membrane segmentation. The IOU scores for

679 each of the new kit images was obtained by selecting ten images at random from a labelled pool

680 of 30 images for training and evaluating the performance on a fixed evaluation set of ten images. 
medRxiv preprint doi: https://doi.org/10.1101/2021.06.23.21258927; this version posted June 25, 2021. The copyright holder for this preprint (which was not certified by peer review) is the author/funder, who has granted medRxiv a license to display the preprint in perpetuity.

It is made available under a CC-BY-NC-ND 4.0 International license .

\begin{tabular}{|c|c|c|c|c|}
\hline \multirow{2}{*}{ Kit name } & \multicolumn{2}{|c|}{ Without adaptation } & \multicolumn{2}{c|}{ With adaptation } \\
\cline { 2 - 5 } & $\begin{array}{c}\text { Zone accuracy } \\
(\boldsymbol{\%})\end{array}$ & $\begin{array}{c}\text { Kit accuracy } \\
(\boldsymbol{\%})\end{array}$ & $\begin{array}{c}\text { Zone accuracy } \\
(\boldsymbol{\%})\end{array}$ & $\begin{array}{c}\text { Kit accuracy } \\
(\boldsymbol{\%})\end{array}$ \\
\hline EcoTest (base) & 98.8 & 96.5 & - & - \\
\hline Flowflex & 93.1 & 86.1 & 99.8 & 99.6 \\
\hline DeepBlue & 93.2 & 86.4 & 99.5 & 100 \\
\hline Jinwofu & 94.7 & 89.4 & 100 & 96.4 \\
\hline $\begin{array}{c}\text { ACON } \\
\text { IgG/IgM }\end{array}$ & 91.0 & 73.6 & 98.8 & - \\
\hline $\begin{array}{c}\text { EcoTest } \\
\text { housing 2 }\end{array}$ & 100 & 100 & - & \\
\hline
\end{tabular}

693 Table 2. Zone-level and kit-level classification accuracy without adaptation (direct testing)

694 and with adaptation. For the direct testing case, the model pretrained on the base kit was

695 directly applied on each of the new kit's evaluation dataset. For the adaptation approach, the

696 pretrained model was adapted to each of the new kits, except for EcoTest housing 2 kit, using

697 10-shot adaptation (20 zone images) and the performance on their respective evaluation datasets

698 is listed here.

699

700

701

702

703

704

705 
medRxiv preprint doi: https://doi.org/10.1101/2021.06.23.21258927; this version posted June 25, 2021. The copyright holder for this preprint (which was not certified by peer review) is the author/funder, who has granted medRxiv a license to display the preprint in perpetuity.

It is made available under a CC-BY-NC-ND 4.0 International license.

a) EcoTest (base kit)

\begin{tabular}{|c|c|c|}
\hline Label & Positive & Negative \\
\hline Positive & (TP) 165 & (FP) 1 \\
\hline Negative & (FN) 3 & (TN) 137 \\
\hline
\end{tabular}

708

709

b) Flowflex (2-zone kit; 224 zone images)

\begin{tabular}{|c|c|c|}
\hline Label & Positive & Negative \\
\hline Positive & (TP) 303 & (FP) 0 \\
\hline Negative & (FN) 1 & (TN) 142 \\
\hline
\end{tabular}

\begin{tabular}{|c|c|c|c|}
\hline $\begin{array}{c}\text { Ambiguity } \\
\text { Region }\end{array}$ & $\begin{array}{c}{[0.50,} \\
0.50]\end{array}$ & $\begin{array}{c}{[0.08,} \\
0.98]\end{array}$ & $\begin{array}{c}{[0.20,} \\
0.80]\end{array}$ \\
\hline Accuracy & $99.8 \%$ & $100 \%$ & $100 \%$ \\
\hline $\begin{array}{c}\text { Percentage } \\
\text { ambiguous } \\
\text { kits }\end{array}$ & - & $5.2 \%$ & $1.3 \%$ \\
\hline
\end{tabular}

c) DeepBlue (2-zone kits; 184 zone images)

\begin{tabular}{|c|c|c|}
\hline Label & Positive & Negative \\
\hline Positive & (TP) 242 & (FP) 0 \\
\hline Negative & (FN) 2 & (TN) 124 \\
\hline
\end{tabular}

\begin{tabular}{|c|c|c|c|}
\hline $\begin{array}{c}\text { Ambiguity } \\
\text { Region }\end{array}$ & $\begin{array}{c}{[0.50,} \\
0.50]\end{array}$ & $\begin{array}{c}{[0.21,} \\
0.95]\end{array}$ & $\begin{array}{c}{[0.20,} \\
0.80]\end{array}$ \\
\hline Accuracy & $99.5 \%$ & $100 \%$ & $100 \%$ \\
\hline $\begin{array}{c}\text { Percentage } \\
\text { ambiguous } \\
\text { kits }\end{array}$ & - & $4.9 \%$ & $4.1 \%$ \\
\hline
\end{tabular}

712

713 d) Jinwofu (2-zone kits; 104 zone image)

\begin{tabular}{|c|c|c|}
\hline Label & Positive & Negative \\
\hline Positive & (TP) 164 & (FP) 0 \\
\hline Negative & (FN) 0 & (TN) 44 \\
\hline
\end{tabular}

\begin{tabular}{|c|c|c|c|}
\hline $\begin{array}{c}\text { Ambiguity } \\
\text { Region }\end{array}$ & $\begin{array}{c}{[0.50,} \\
0.50]\end{array}$ & $\begin{array}{c}{[0.05,} \\
0.99]\end{array}$ & $\begin{array}{c}{[0.20,} \\
0.80]\end{array}$ \\
\hline Accuracy & $100 \%$ & $100 \%$ & $100 \%$ \\
\hline $\begin{array}{c}\text { Percentage } \\
\text { ambiguous } \\
\text { kits }\end{array}$ & - & $1.4 \%$ & 0 \\
\hline
\end{tabular}

714

e) $\mathrm{ACON} \operatorname{IgG} / \operatorname{IgM}$ (3-zone kits; 193 zone images) 
medRxiv preprint doi: https://doi.org/10.1101/2021.06.23.21258927; this version posted June 25, 2021. The copyright holder for this preprint (which was not certified by peer review) is the author/funder, who has granted medRxiv a license to display the preprint in perpetuity.

It is made available under a CC-BY-NC-ND 4.0 International license .

\begin{tabular}{|c|c|c|}
\hline Label & Positive & Negative \\
\hline Positive & (TP) 386 & (FP) 1 \\
\hline Negative & (FN) 6 & (TN) 192 \\
\hline
\end{tabular}

\begin{tabular}{|c|c|cc|}
\hline $\begin{array}{c}\text { Ambiguity } \\
\text { Region }\end{array}$ & $\begin{array}{c}{[0.50,} \\
0.50]\end{array}$ & $\begin{array}{c}{[0.11,} \\
0.88]\end{array}$ & $\begin{array}{c}{[0.20,} \\
0.80]\end{array}$ \\
\hline Accuracy & $98.8 \%$ & $99.5 \%$ & $99.3 \%$ \\
\hline $\begin{array}{c}\text { Percentage } \\
\text { ambiguous } \\
\text { kits }\end{array}$ & - & $3.5 \%$ & $2.8 \%$ \\
\hline
\end{tabular}

717 f) EcoTest housing 2 (3-zone kits; 24 zone image).

\begin{tabular}{|c|c|c|}
\hline Label & Positive & Negative \\
\hline Positive & (TP) 66 & (FP) 0 \\
\hline Negative & (FN) 0 & (TN) 6 \\
\hline
\end{tabular}

Table 3. Confusion matrices of the best models applied on the evaluation dataset (left)

\section{Accuracy and the percentage of ambiguous kits across varying ambiguity regions (right)}

721 (a) is the confusion matrix for the base model on base kit evaluation set. The performance of the

722 best performing adapted model on the evaluation dataset for each of the new kits $(\mathbf{b}-\mathbf{e})$ without

723 the enforcement of an ambiguity region is shown in the tables to the left. (f) shows the confusion

724 matrix for the EcoTest housing 2 kit. The tables on the right show the accuracy for the

725 corresponding assay kit and percentage of kits classified as ambiguous values for the different

726 kits when varying the ambiguity region. 
medRxiv preprint doi: https://doi.org/10.1101/2021.06.23.21258927; this version posted June 25, 2021. The copyright holder for this preprint (which was not certified by peer review) is the author/funder, who has granted medRxiv a license to display the preprint in perpetuity.

It is made available under a CC-BY-NC-ND 4.0 International license .

a

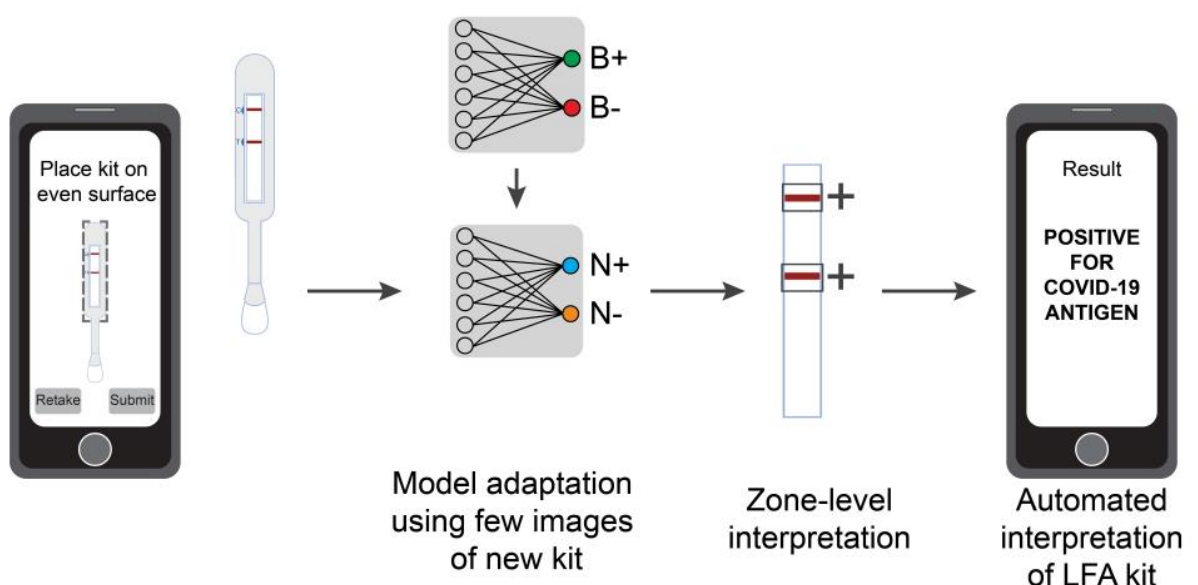

b

Base kit

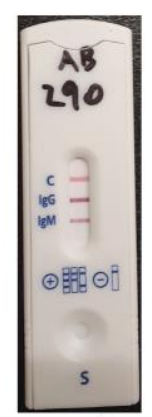

$\varepsilon^{0 e^{\delta^{x}}}$

d

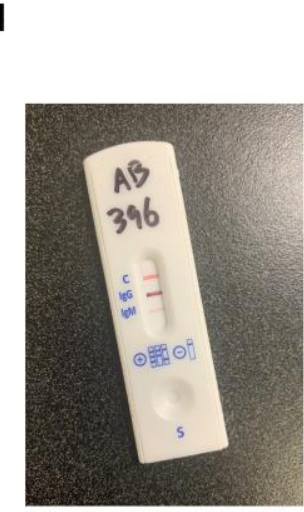

Assay kit (raw input image)
New kits

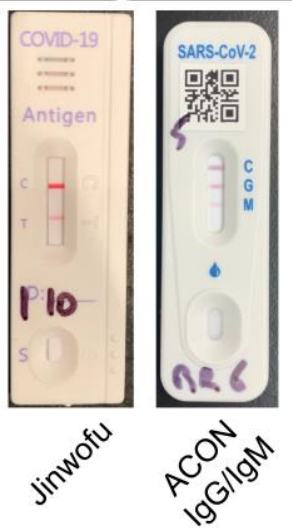

Image pre-processing

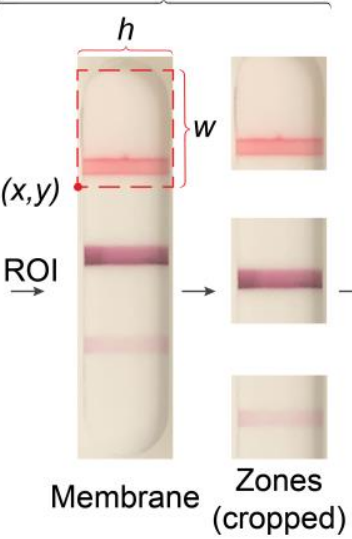

C False positive predictions
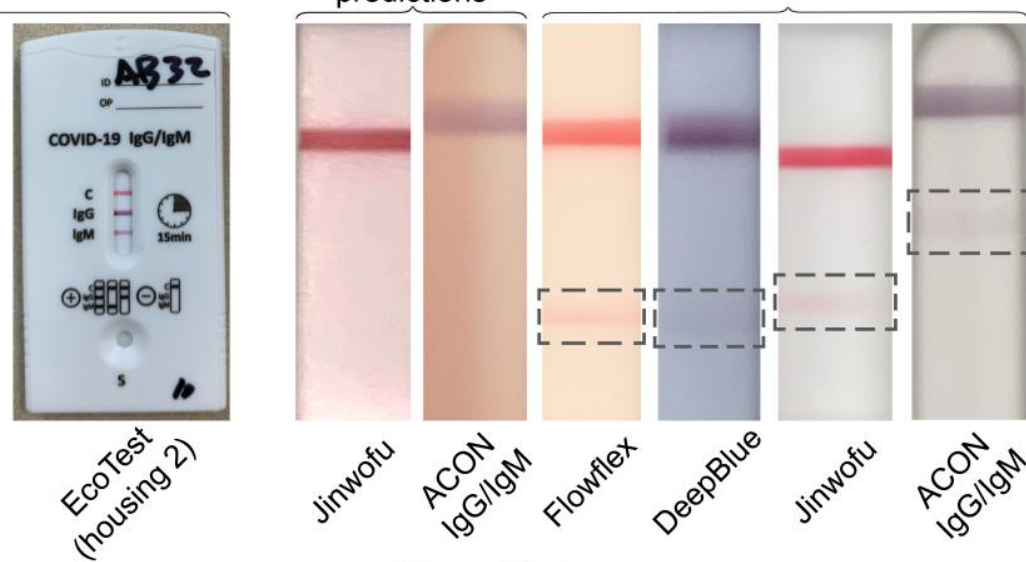

Kit classification

\section{Figure 1. Overview of use case, challenge, and pipeline for image processing and machine}

734 learning. (a) Envisioned testing process for end user. The user takes an image of the assay kit 
medRxiv preprint doi: https://doi.org/10.1101/2021.06.23.21258927; this version posted June 25, 2021. The copyright holder for this preprint (which was not certified by peer review) is the author/funder, who has granted medRxiv a license to display the preprint in perpetuity.

It is made available under a CC-BY-NC-ND 4.0 International license .

735 using a smartphone displaying an on-screen image guide. The zones containing the bands are

736 automatically identified, and a model that was pre-trained on a base kit (shown as " $\mathrm{B}$ " in the

737 network) and previously rapidly adapted to a new kit (using few-shot learning, shown as "N" in

738 the network) processes the images of zones. The model classifies each zone as positive or

739 negative, and provides an overall assay result on the screen of the smartphone. The cloud-hosted

740 model processes the image and generates the results in $\sim 4$ seconds. (b) Images of a base LFA kit

741 (EcoTest) for pre-training the model, and five new COVID-19 LFA kits (including both antigen

742 and antibody tests) to be interpreted. (c) Images illustrating the challenge for few-shot learning.

743 A pre-trained model on the base kit, without adaptation, produces failed predictions on the new

744 kits. Shown are both false positives and false negatives (likely due to variations in colors and

745 intensities of membrane background and bands). (d) Overview of AutoAdapt LFA pipeline.

746 From a raw input image of an assay kit, a correction of orientation and perspective is applied to

747 segment an image of an assay kit. From the assay kit image, a segmentation model based on

748 Mask R-CNN is used to extract the membrane region of interest (RoI). Based on measured kit-

749 specific parameters, individual zones are cropped, and passed through a software pipeline

750 consisting of a feature extractor followed by a binary classifier. Classification of each zone

751 allows, via a kit-specific lookup table, for a final classification of assay result ("kit-level"

752 classification or result) as positive, negative, or invalid. 
medRxiv preprint doi: https://doi.org/10.1101/2021.06.23.21258927; this version posted June 25, 2021. The copyright holder for this preprint (which was not certified by peer review) is the author/funder, who has granted medRxiv a license to display the preprint in perpetuity.

It is made available under a CC-BY-NC-ND 4.0 International license .

\section{a}

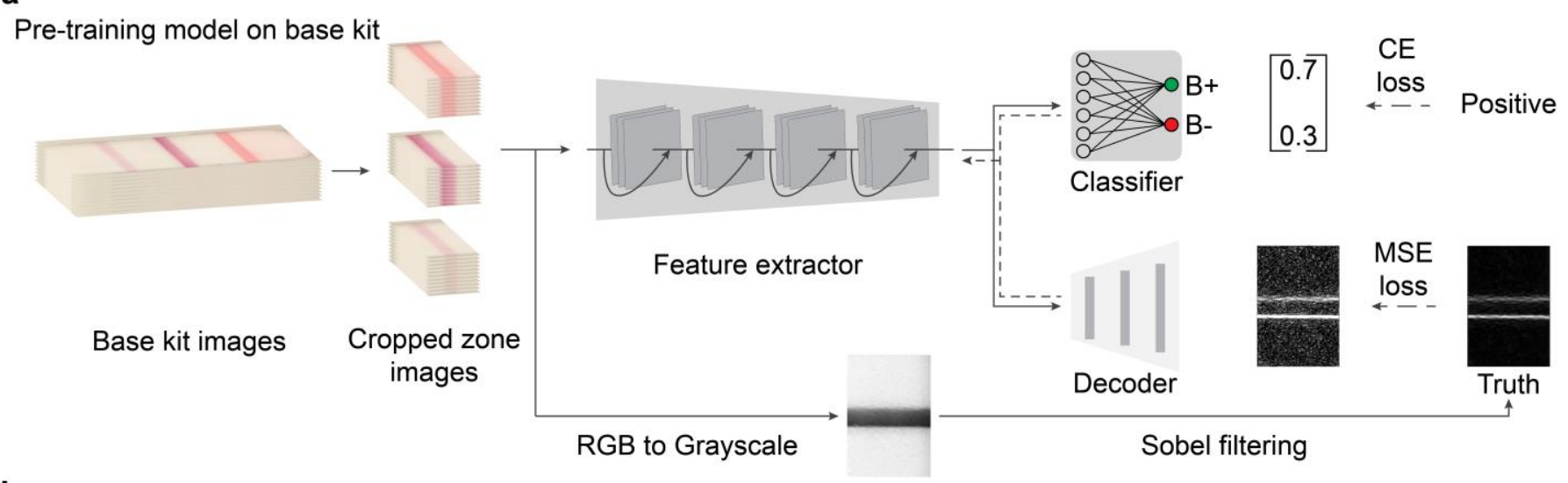

b

Adapting model to new kit

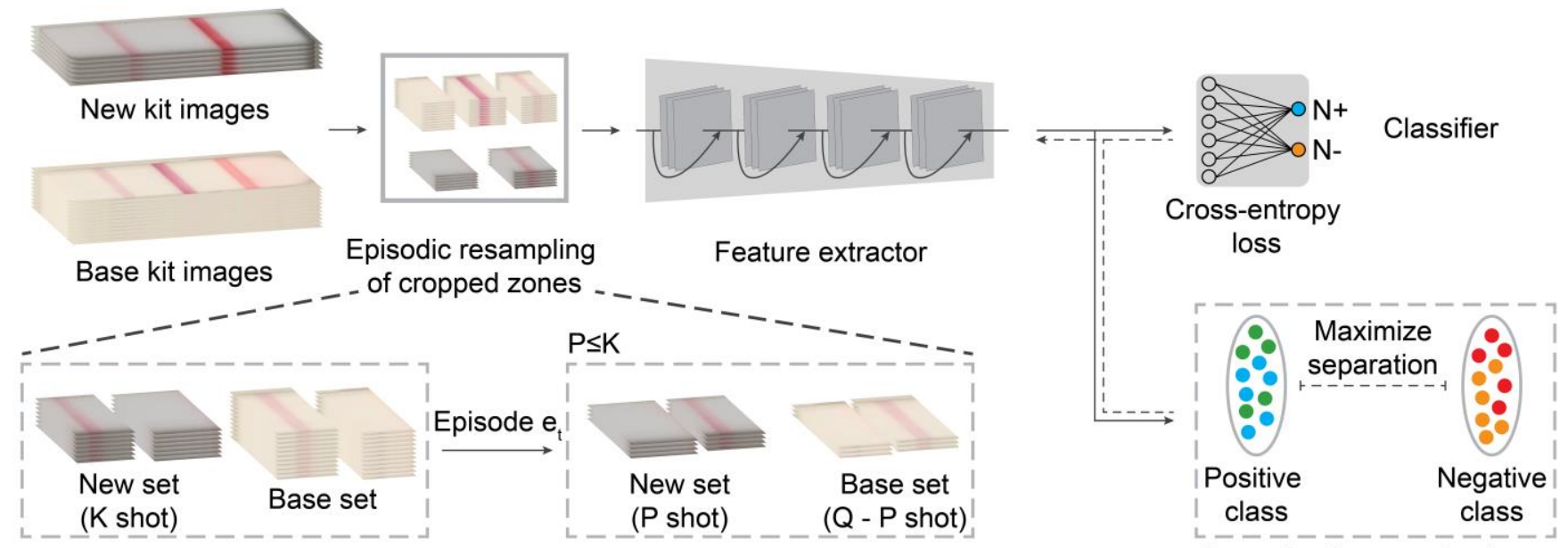

Figure 2. Self-supervision and few-shot adaptation for LFA kits. (a) The feature extractor is

755 pretrained on the base kit using self-supervised learning task over edge-filtered patterns and

756 fully-supervised binary classification task. For each zone, fully-supervised binary classification

757 is carried out with cross-entropy loss with the annotated binary labels. Sobel filter is used to

758 highlight the edge pixels between the band and the background of the membrane. The edge

759 image after normalization is used as ground truth and the learning process is used to reconstruct

760 an image that resembles the ground truth edge image, with the quality measured in MSE (Mean

761 Square Error). The solid and dashed arrows indicate forward processing and gradient

762 backpropagation respectively during the learning process. (b) Model adaptation is carried out by 
medRxiv preprint doi: https://doi.org/10.1101/2021.06.23.21258927; this version posted June 25, 2021. The copyright holder for this preprint (which was not certified by peer review) is the author/funder, who has granted medRxiv a license to display the preprint in perpetuity.

It is made available under a CC-BY-NC-ND 4.0 International license.

763 supervised contrastive learning to regularize the feature extractor and fully-supervised learning

764 to learn an adapted classifier for the new kit. A sampling strategy to build an episode with Q

765 (e.g., 32) images per class is used: for each class (positive or negative), given K (e.g., 10) images

766 available, P (e.g., 4) images are subsampled from the new kit and mixed with Q-P images of the

767 base kit. 
medRxiv preprint doi: https://doi.org/10.1101/2021.06.23.21258927; this version posted June 25, 2021. The copyright holder for this preprint (which was not certified by peer review) is the author/funder, who has granted medRxiv a license to display the preprint in perpetuity.

It is made available under a CC-BY-NC-ND 4.0 International license.
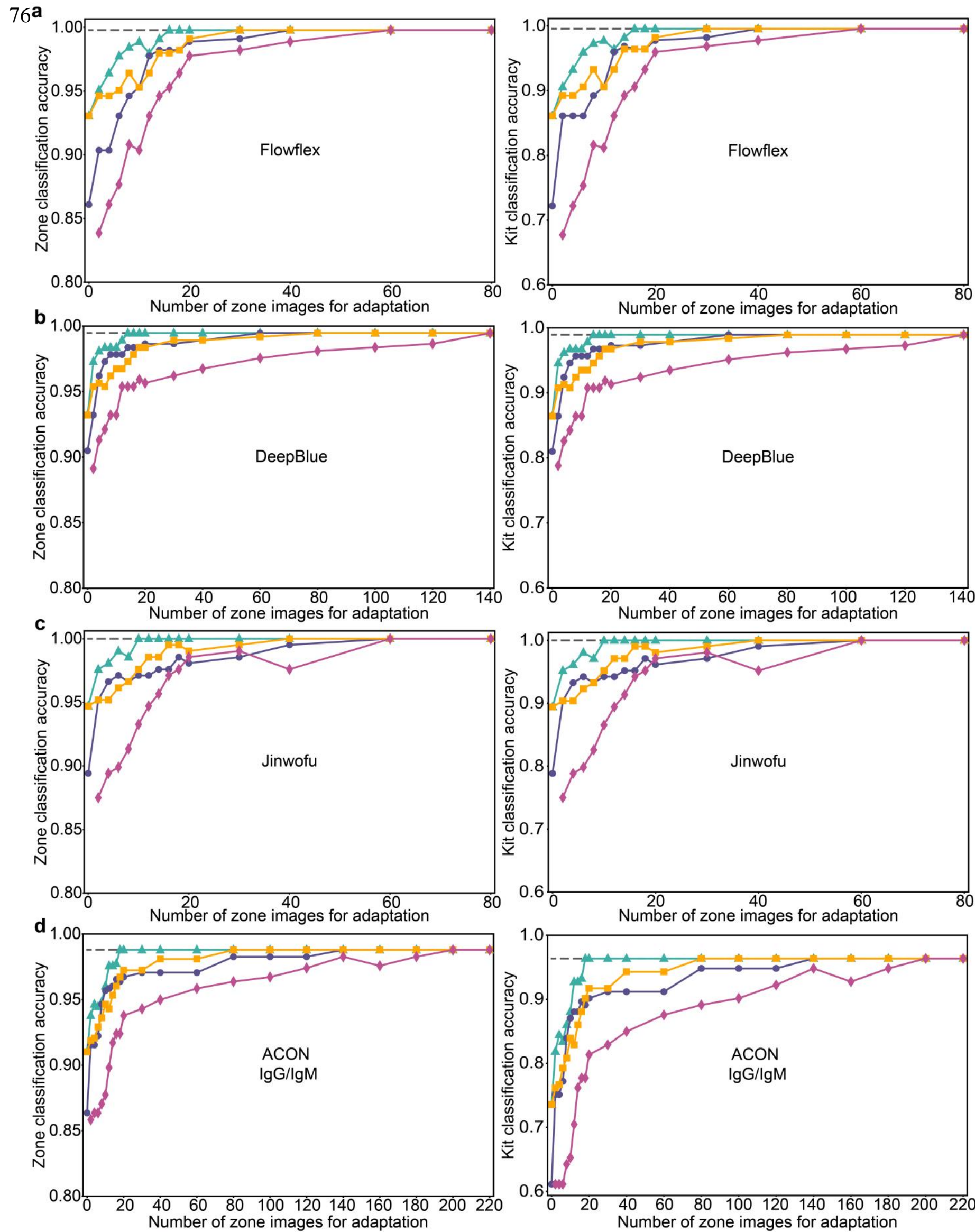

$\begin{array}{ll}-- \text { Maximum } & \rightarrow \text { Self-supervision and supervised contrastive loss } \\ \rightarrow-\text { Supervised contrastive loss only }\end{array}$

-- Self-supervision only

$\rightarrow$ No self-supervision and no supervised contrastive loss 
medRxiv preprint doi: https://doi.org/10.1101/2021.06.23.21258927; this version posted June 25, 2021. The copyright holder for this preprint (which was not certified by peer review) is the author/funder, who has granted medRxiv a license to display the preprint in perpetuity.

It is made available under a CC-BY-NC-ND 4.0 International license.

769 Figure 3. Zone-level and kit-level classification accuracies for four new COVID-19 LFA

770 kits shown with ablated models and number of new kit training images. Ablation studies

771 were carried out to analyze the relative contributions of self-supervised learning for feature

772 extraction and supervised contrastive learning for adaptation. Each model was evaluated by

773 varying the number of images used in the adaptation. Zone-level accuracy scores (left) and kit-

774 level accuracy scores (right) reported for four new assay kits, (a) Flowflex, (b) DeepBlue, (c)

775 Jinwofu and (d) ACON IgG/IgM. (The EcoTest housing 2 kit was identical in all aspects to the

776 base kit expect for the housing, so the direct application of the base model without any

777 adaptation was able to achieve $100 \%$ zone-level and kit-level accuracies.) The maximum

778 accuracy indicates the upper bound attained by training a model from scratch using all training

779 images for each kit. 